\title{
El «nacionalismo metodológico» como obstáculo en la investigación sociológica sobre migraciones internacionales
}

\author{
RAMÓN LlOPIS GOIG* \\ Universidad de Valencia \\ ramon.llopis@uv.es
}

Recibido: 21.11.2006

Aceptado: 29.05 .2007

\section{INTRODUCCIÓN}

Durante los últimos años la transformación de España en destino migratorio ha dado lugar a la realización de numerosos estudios sociológicos tanto en el ámbito estatal, como en el autonómico y local. Estos estudios sociológicos se puede clasificar en tres grandes grupos. En primer lugar, los registros estadísticos destinados a obtener estimaciones de los movimientos migratorios, mediante mediciones de los flujos migratorios y los stocks de población inmigrante. En segundo lugar, aunque en un grado muy inferior, se han realizado investigaciones destinadas a ahondar en el proceso de integración de la población inmigrante en las sociedades receptoras o de acogida. En tercer lugar, se han llevado a cabo investigaciones dirigidas a estudiar las actitudes y las opiniones de la población autóctona hacia la población inmigrante. La principal preocupación que orienta la realización de estos últimos estudios es la identificación de las reacciones de la población autóctona ante el asentamiento de extranjeros dentro de nuestras fronteras.

El primer tipo de estudios, las estadísticas de flujos migratorios, se refieren habitualmente al conjunto de movimientos (entradas y salidas) producidos durante un año natural y tienen como objeto la medición de los movimientos o desplazamientos efectuados en un contexto concreto. Por otro lado, los registros de stocks tienen como objeto a personas, ya que en ellos se contabiliza el volumen

* Doctor en Sociología y Profesor del Departamento de Sociología y Antropología Social de la Facultad de Ciencias Sociales de la Universidad de Valencia. Avenida dels Tarongers s/n. (Edificio Oriental) 46022 Valencia. E-mail: ramon.llopis@uv.es. 
de población inmigrante que reside en un país en un momento determinado. Estos estudios se suelen ver afectados por dificultades relacionadas con el carácter polietápico y dinámico del propio proceso migratorio, el tipo de relación que los sujetos migrantes mantienen con el país de origen y destino, la falta de acuerdo en la categorización de los movimientos como internos o externos y la introducción de nuevas clasificaciones de los movimientos como consecuencia de la creación de espacios de movilidad diferenciados.

El segundo tipo de estudios, realizados directamente a la población inmigrante, se centra en la obtención de descripciones sociodemográficas y en la búsqueda de explicaciones referidas a las pautas de asentamiento en entornos urbanos, así también como a la evaluación del proceso de inserción en el nuevo contexto y el análisis de las motivaciones y los antecedentes que han originado el proceso de emigración. Estos estudios se ven afectados por diversas dificultades técnicas, casi todas ellas relacionadas con la diversidad cultural y las condiciones de movilidad y marginación en que se encuentra la mayor parte de la población inmigrante. Se trata de dificultades que, en términos generales, tienen que ver con una concepción de las minorías étnicas como grupos culturales homogéneos y estáticos, con el uso de categorías culturales excesivamente amplias, con la atribución de diferencias observadas a la pertenencia a grupos culturales diferentes, y finalmente, con las dificultades de operacionalización propias de conceptos relacionados con la cultura. Así mismo, habría que mencionar la existencia de dificultades relacionadas con la adopción de diseños de investigación inadecuados, así como la elección de instrumentos de investigación y procedimientos de muestreo no exentos de deficiencias.

El tercer tipo de estudios se ha realizado mediante la aplicación de encuestas estadísticas a la población general. Esta técnica se ha enfrentado a dificultades relacionadas con la conceptualización del objeto de estudio, la medición de las actitudes, la coherencia entre actitudes y comportamientos, los procedimientos de muestreo, los diseños de investigación, los problemas de inferencia derivados de los diseños de investigación adoptados y la interpretación de los datos.

Este trabajo se sitúa en un contexto de preocupación por la necesidad de superar esas dificultades técnicas. Ahora bien, lo que defendemos en este artículo es que esos problemas técnicos sólo podrán ser superados en la medida en que las soluciones que se planteen vayan más allá del plano técnico y se sitúen en el marco epistemológico y metodológico. Asumimos la distinción que realizó Ibáñez (1994: 57) en la que señalaba la existencia de tres niveles en investigación social: el epistemológico, el metodológico y el técnico ${ }^{1}$. Partimos de la idea de que estos problemas técnicos no son específicos del estudio sociológico de las migraciones internacionales, sino que es el estudio de éstas últimas el que permite que los mencionados problemas afloren y se manifiesten con rotundidad.

1 Siguiendo a Bourdieu, Chamboredou y Passeron (1976), que a su vez seguían a Bachelard (1949).

EMPIRIA. Revista de Metodología de Ciencias Sociales. N. ${ }^{\text {13 }}$, enero-junio, 2007, pp. 101-117. ISSN: 1139-5737 
Nuestra hipótesis es que una parte de los problemas técnicos a los que hemos hecho alusión, son una consecuencia de que la mayoría de las prácticas de investigación social siguen arrastrando, y dando tácitamente por válidas, algunas de las ideas originadas en los albores de la modernidad, cuando nació la sociología y se gestaron los principios básicos de sus actuales métodos y técnicas de investigación social. Paralelamente al surgimiento de la ciencia social, la modernidad fue la fase histórica de consolidación del estado-nación como unidad de organización de la vida social y política. Esta coincidencia temporal hizo que la centralidad de este último se incrustara en las entrañas de la ciencia sociológica y se convirtiera en un presupuesto instalado en el corazón de las prácticas de investigación social de la mayor parte de la comunidad sociológica. Durante los últimos años, cuando el proceso de globalización de la vida social en que se encuentran la humanidad ha intensificado las interconexiones globales y los marcos estatales-nacionales se han visto desbordados, diversos autores han señalado los inconvenientes producidos por la prolongación de la asunción implícita de este síndrome al que algunos han denominado «modelo estadocéntrico» (Wallerstein 1974, 1996; Sklair 1995), «nacionalismo metodológico» (Smith 1979; Beck 2004, 2005) o «teoría del contenedor de la sociedad» (Beck 1999). La asunción implícita de este presupuesto, que implica la suposición de que el estado-nación es el contenedor de la sociedad, genera planteamientos contraproducentes para el estudio de fenómenos como las migraciones internacionales.

Este trabajo examina el modo en que ese presupuesto epistemológico, asumido implícitamente y generalmente no problematizado en la práctica de la investigación social, genera problemas técnicos tanto si se trata de estudios dirigidos a la población inmigrante, como si se refieren a la población autóctona. Nuestro análisis se sitúa, por tanto, en el nivel de las prácticas de investigación social, donde la inercia de este presupuesto epistemológico se refleja, por ejemplo, en las conceptualizaciones de los grupos, en el modo de formular preguntas, en la medición de las actitudes, en la confección de las muestras, en la selección y captación de los entrevistados y en el diseño de la investigación.

De acuerdo con ese objetivo general, nuestro plan de trabajo procede como sigue. En el segundo apartado se introduce el concepto de nacionalismo metodológico y se realizan unas breves referencias históricas y políticas relativas al proceso de formación del estado-nación como forma de organización política. A continuación se examinan las principales dificultades técnico-metodológicas que el estudio de las migraciones internacionales ocasiona a la ciencia sociológica. En este apartado se señala que la asunción implícita del nacionalismo metodológico es un problema que se manifiesta en la investigación sobre migraciones internacionales, si bien no afecta única y exclusivamente a las investigaciones en esta área. 


\section{EL NACIONALISMO METODOLÓGICO Y LA INVESTIGACIÓN SOCIOLÓGICA}

Los seres humanos que vivieron hace mil años sabían pocas cosas en torno a lo que sucedía pocos kilómetros más allá de donde habían nacido. La mayor parte de las interacciones culturales tenían lugar entre las élites o bien en ámbitos locales restringidos, ya que antes del surgimiento de los estados-nación, la vida, para la mayoría de la población, comenzaba, transcurría y acababa en la misma localidad en que se había nacido.

Con la modernidad, ese escenario identitario se vio profundamente alterado por el auge del estado-nación como forma de organización política, así como por el creciente empuje de los movimientos nacionalistas. La población comenzó a desarrollar una conciencia de pertenencia al marco estatal-nacional, a la que contribuyeron factores como el interés de las clases dominantes y los gobiernos por crear una nueva identidad que legitimara el aumento del poder del estado (Breully 1992); la creación de un marco cognitivo compartido por medio del desarrollo de sistemas de educación masivos (Gellner 1983); la aparición de sistemas de comunicación que posibilitaron la difusión de mitos nacionales y «comunidades imaginadas» (Anderson 1983); y la consolidación de una cultura pública de derechos y deberes compartidos que haría posible la movilidad social de sus miembros dentro de un territorio delimitado (Smith 1986).

En los últimos años, sin embargo, se han comenzado a producir un resquebrajamiento del entramado moderno de los estados-nación. Los estados están cada vez más sumidos en redes de interconexión regional y global, penetradas por fuerzas supranacionales, intergubernamentales y transnacionales. La globalización está produciendo una separación entre la lógica estatal y societal, en virtud de su incidencia en la reducción de las capacidades de los estados-nación de actuar independientemente en la articulación y consecución de objetivos políticos nacionales e internacionales. Las actividades económicas, sociales y políticas desbordan cada vez más las fronteras nacionales, desafían el principio territorial en que se apoyaba el estado moderno, según el cual hay una correspondencia entre sociedad, economía y estado. Todo ello no hace sino cuestionar un presupuesto fundamental de la primera modernidad según el cual los contornos de la sociedad eran mayoritariamente coincidentes con los del estado-nación.

En algunas de sus obras, el sociólogo alemán Ulrich Beck ha reconducido el debate sobre estas trasformaciones culturales de la modernidad al terreno epistemológico y ha planteado la necesidad de un viraje metodológico en la sociología actual. Beck sostiene que en la actualidad estamos entrando en una fase, que él denomina «segunda modernidad», en la que el modelo de la «primera modernidad» comienza a ser cuestionado, al basarse éste último en la ya aludida unidad entre identidad cultural, territorio y estado. Si el estado-nación propio de la «primera modernidad» basó su poder en el apego a un lugar concreto, la sociedad global actual asiste, a resultas de la globalización, a una ramificación de dimensiones que se entremezclan con el estado-nación, a una multiplicidad de 
círculos sociales, redes de comunicación, relaciones de mercado y modos de vida que traspasan en todas direcciones las fronteras territoriales del estado-nación. La globalización está sacudiendo la imagen de los estados-nación como espacios cerrados, homogéneos y estancos, activando un proceso de desnacionalización, que deja sin fundamento una de las premisas esenciales de la «primera modernidad», a saber, la idea de que vivimos y actuamos en los espacios cerrados y recíprocamente delimitados de los estados-nación y de sus respectivas sociedades nacionales (Beck 1999: 41-42).

Nos interesa subrayar el extraordinario impacto que este proceso tiene sobre la propia sociología, ya que la simultaneidad germinal de la sociología como ciencia y del estado-nación como fórmula de organización política moderna, ha determinado que la primera arrastre, aún en la actualidad, una serie de presupuestos metodológicos que son deudores de la ontología social prevaleciente en ese periodo que Beck denomina «primera modernidad». La sociología fue fruto de las inmensas transformaciones sociales que tuvieron lugar hace algo más de doscientos años: la Revolución Francesa y la Revolución Industrial del siglo XVII, disolvieron las formas de organización social bajo las cuales los hombres habían vivido durante milenios (Giddens 1986). El desmoronamiento de las estructuras sociales existentes despertó la reflexión rigurosa y científica sobre la naturaleza de la sociedad y los cambios sociales de entonces. La Sociología se desarrolló tratando de explicar transformaciones tan importantes como las de finales del siglo XVIII y XIX.

El momento histórico en que nació la sociología determinó que ésta se viera dominada por la perspectiva implícita de que las sociedades podían estudiarse como unidades independientes. Pese a que los fundadores de la sociología fueron muy proclives a estudiar sociedades distintas de la suya propia y a recurrir a los análisis comparativos, la mayoría de sus seguidores consideraron a estas sociedades como entidades separadas (Cohen y Kennedy 2000). Esta visión fue adquiriendo centralidad en la comprensión de la dinámica y estructura interna de las sociedades, su especificidad histórica y tradiciones culturales, sus patrones únicos de desigualdad y sus particulares direcciones de cambio social. Así, la sociología se entendió a sí misma como la ciencia de la sociedad moderna y presupuso el dominio estatal del espacio social, lo que venía a significar que la visión sociológica era una resultante de la autoridad ordenadora del estado-nación. Así, las sociedades eran sociedades estatales y el orden de la sociedad no era más que el orden estatal. Dentro de esos esquemas mentales e institucionales las sociedades «modernas» se convirtieron en sociedades individuales, delimitadas las unas respecto de las otras, pero recogidas como en un contenedor, dentro del espacio de poder de los estados nacionales. Además, este esquema de ordenamiento también se hacía valer en el interior de los estados, en cuyo espacio el control estatal creaba una homogeneidad interna mediante la regulación de la totalidad de las prácticas sociales: mercado de trabajo, producción, cultura, deporte, enseñanza e idioma, que quedaban acuñadas desde una perspectiva nacional. En este contexto, el estado aducía, en su calidad de contenedor, una 
unidad territorial en la que se realizaban sistemáticamente estadísticas sobre procesos y aspectos económicos y sociales, de tal manera que las categorías de la auto-observación estatal se convertían en categorías de las ciencias sociales empíricas, y veían confirmar las definiciones de la realidad de índole sociológica y burocrática (Beck 1999: 47).

Este principio axiomático de la sociología de la primera modernidad se está viendo sacudido en la actualidad, si bien la visión que de él se desprende sigue siendo predominante en un buen número de planteamientos de investigación social. A resultas de ello, numerosas prácticas de investigación se ven afectadas por la mutilación que supone esa asunción implícita². Beck llama «nacionalismo metodológico» a la continuidad, más allá del periodo histórico de su vigencia, de la asunción de la equiparación entre estado, sociedad nacional y territorio. Habla de «mirada nacional» cuando los actores sociales comparten la fe en la equiparación señalada, y de «nacionalismo metodológico» cuando la mencionada mirada determina las perspectivas de observación científica (Beck 2006: 38-39). Así pues, el reproche al «nacionalismo metodológico», no tiene nada que ver con el hecho de que determinados sociólogos sean nacionalistas. También los no nacionalistas pueden estar investigando desde ese marco de referencia estadocéntrico. El campo de estudio de las migraciones internacionales ayudará a mostrar esto.

\section{PROBLEMAS TÉCNICO-METODOLÓGICOS EN EL ESTUDIO DE LAS MIGRACIONES INTERNACIONALES}

Este trabajo partía de la consideración de que los métodos y técnicas de investigación social, concebidos en el mismo contexto histórico en que nació la sociología como ciencia, deben ser revisados en la actualidad. Hay una gran diferencia entre las sociedades actuales y las sociedades que vieron nacer y desarrollarse a la sociología, de tal suerte que los presupuestos epistemológicos y metodológicos implícitos en fases anteriores deben ser puestos al día, si se pretende que la investigación social aborde de manera exitosa nuevos objetos de estudio que no emergen del «orden internacional de los estados», sino de un mundo crecientemente interconectado y globalizado. En este apartado señalamos cuatro grandes bloques de problemas que habitualmente se producen en la investigación social de las migraciones transnacionales cuando ésta es incapaz de superar el nacionalismo metodológico. En primer lugar nos referimos a la mutilación del objeto de estudio que produce este síndrome cuando se enfrenta a objetos de estudio internacionales y transnacionales. En segundo lugar consideramos algunas dificultades conceptuales relacionadas con la categorización. En

${ }^{2}$ Beck se refiere a diversos ámbitos de investigación como paradigmáticos a la hora de mostrar las dificultades que causa la asunción implícita del «nacionalismo metodológico», como por ejemplo el comercio internacional, las desigualdades sociales o el terrorismo internacional (Beck 2004: 47-57). Sin embargo, sólo se ocupa marginalmente de las migraciones transnacionales y sin considerar sus implicaciones metodológicas (Beck 2005: 144).

EMPIRIA. Revista de Metodología de Ciencias Sociales. N. ${ }^{0}$ 13, enero-junio, 2007, pp. 101-117. ISSN: $1139-5737$ 
tercer lugar examinamos la problemática delimitación de los universos de estudio. Por último, nos ocupamos de las dificultades para elaborar muestras representativas. En los cuatro casos se producen distorsiones y problemas técnicos como consecuencia de la implícita consideración de la sociedad como un bloque nacionalmente homogéneo. Veámoslo a continuación.

\section{La mutilación del objeto de estudio}

El primer aspecto que queremos enfatizar para abordar los problemas derivados del nacionalismo metodológico en la investigación sociológica sobre migraciones internacionales es el hecho de que la mayor parte de estas investigaciones suelen ser encargadas o financiadas por las administraciones públicas. Esto hace que estos estudios se vean fuertemente afectados por las necesidades propias de la actividad político-administrativa, una circunstancia que, en términos generales, frena el desarrollo de una reflexión científica sobre el fenómeno de las migraciones internacionales. Este hecho va a contribuir decisivamente a la gestación de una de las principales dificultades de los estudios sobre población inmigrante en contextos de recepción. Dado que lo habitual en los estudios sobre inmigración internacional es que sea la administración (estatal, autonómica o local) las que los encarga, será también habitual que los investigadores adopten el correspondiente ámbito territorial como marco natural de investigación. Ello supone confundir objeto social y objeto de estudio sociológico, «pues el hecho de que al estado le interese conocer los fenómenos o procesos que se dan en su territorio no significa que estos se puedan comprender cabalmente sin tener en cuenta lo que ocurre más allá de sus fronteras» (García Borrego 2001: 150). Y esto genera uno de los más graves problemas de la investigación sociológica sobre inmigración que se realiza en España: una carencia radical de investigación sobre lo que sucede en las sociedades de origen ${ }^{3}$. Mientras comienza a ser relativamente abundante la literatura sobre las condiciones de la inmigración, son poco frecuentes las investigaciones centradas en las condiciones sociales que dan lugar a la emigración, así como a las transformaciones operadas por ésta en las sociedades de origen (Mohatar et alii 2004: 11). En este contexto, el conocimiento que se obtiene se caracteriza por la frecuente reproducción de las categorías institucionales y la mutilación del objeto de estudio, al establecerse una línea divisoria entre emigración e inmigración, que impide entender las condiciones de producción y reproducción de la inmigración a partir de las condiciones de partida y de los efectos de la emigración en las propias sociedades de origen (Sayad 1984, 1996).

Ante todo esto, habría que señalar, en primer lugar, que la consideración del fenómeno de la inmigración como un fenómeno interno del sistema global

${ }^{3}$ Una excepción serían los trabajos de Tornos et alii (1997), Gregorio (1998), Ramírez (1998), Suárez (1998), Escrivá (2003), Vallejo (2004) y Lacomba (2004).

EMPIRIA. Revista de Metodología de Ciencias Sociales. N. ${ }^{0}$ 13, enero-junio, 2007, pp. 101-117. ISSN: $1139-5737$ 
siempre ofrecerá un prisma analítico superior a todos aquellos enfoques que, atrapados por esta «miopía estadocéntrica» que provoca el nacionalismo metodológico, consideren los movimientos migratorios como algo que tiene lugar entre estados separados. Los miembros de Ioé ya señalaron que «los análisis de este fenómeno "basados en un solo país" suponen un recorte inadmisible del fenómeno desde el punto de vista analítico, y sólo pueden sostenerse desde determinadas estrategias de control o utilización de los inmigrantes, o concepciones ideológicas considerando el estado-nación como el ámbito "natural" desde el que debe analizarse el fenómeno» (Ioé 1999: 213). Esa naturalización del estado-nación como ámbito desde el que analizar un fenómeno como el de la inmigración sería, pues, la prueba más evidente de los efectos perniciosos de la «miopía estadocéntrica» en los planteamientos de los investigadores sociales. Así, dado que en principio es lógico que desde la visión del estado se impongan delimitaciones territoriales, lo que habría que preguntarse al respecto es porque los propios investigadores no plantean diseños de investigación que, al igual que el propio fenómeno migratorio, presenten escenarios territoriales superiores al estado-nación.

\section{Los problemas conceptuales y las dificultades de categorización}

Al hablar de los problemas de conceptualización y categorización nos referimos a un amplio conjunto de problemas que aparecen en dos frentes. Por un lado, los problemas de categorización que se presentan en los estudios estadísticos destinados a la medición de los flujos migratorios. Por otro, los problemas conceptuales relacionados con las diferencias idiomáticas y culturales que se generan en la elaboración de instrumentos de investigación.

Por lo que se refiere a los problemas conceptuales que aparecen en los estudios estadísticos destinados a la medición de los flujos migratorios, la primera dificultad, que afecta tanto a flujos como a stocks, tiene que ver con la idiosincrasia de los sujetos migrantes y el tipo de relación que mantienen tanto con el país de origen como con la comunidad de destino ${ }^{4}$. Nos referimos a la confusión que, en ocasiones, impide saber si los datos se encuentran clasificados en función del lugar de origen del desplazamiento, el lugar de nacimiento del inmigrante o la nacionalidad del inmigrante. La segunda dificultad se deriva de la falta de acuerdo en la categorización de los movimientos como «internos»o «externos». Aunque se podría considerar como «internas» a aquellas migraciones en las que la comunidad emisora y receptora pertenecen al mismo país, y «externas» a aquellas en las que pertenecen a diferentes países, esto no siempre es así y de ahí la existencia de confusión. Algunos organismos dedicados a la producción de datos estadísticos pertenecientes a ámbitos administrativos inferiores al estatal recurren a estos conceptos con una semántica diferente. El tercer tipo de problemas conceptuales tiene que ver con la introducción de nuevas clasificaciones deriva-

${ }^{4}$ Seguimos el esquema propuesto por Cristina Blanco (2000: 84-88).

EMPIRIA. Revista de Metodología de Ciencias Sociales. N. ${ }^{0}$ 13, enero-junio, 2007, pp. 101-117. ISSN: $1139-5737$ 
das de la creación de espacios de movilidad diferenciados, como por ejemplo la Unión Europea, donde los acuerdos de movilidad geográfica establecen diferenciaciones y se hace necesario distinguir entre inmigrantes que llegan a un país de la UE en función de si son ciudadanos de otro país de la UE o si lo son de terceros países. Dichas diferenciación se aprecia en las propias estadísticas migratorias de la Unión Europea, en las que se distingue entre inmigrantes comunitarios y no comunitarios ${ }^{5}$.

En cuanto a los instrumentos de investigación, es muy habitual que en la investigación con inmigrantes se recurra sino a cuestionarios, preguntas y escalas concebidas originariamente para la población autóctona, si al menos a ciertos presupuestos conceptuales que le son propios. Sin embargo, las diferencias idiomáticas y culturales de la población inmigrante afectan a la fiabilidad y validez de los instrumentos de medida. Por eso, cualquier estudio con inmigrantes debería garantizar, en primer lugar, que la minoría o minorías étnicas en cuestión tienen un conocimiento suficiente de la lengua en la que se va a realizar la investigación; y en segundo lugar, que tanto en los casos en que está garantizado el conocimiento suficiente de una segunda lengua, como en los casos en que se realiza una adaptación a la lengua minoritaria, hay una equivalencia lingüística de las preguntas o escalas. Por todo ello, es necesaria la realización de pruebas pretest, investigación exploratoria, traducciones paralelas de cuestionarios, análisis de fiabilidad comparados (por grupos nacionales) y entrevistadores bilingües.

\section{La compleja delimitación del universo de estudio}

Una parte de los problemas que se plantean en la investigación social de la inmigración tiene que ver con la delimitación de los grupos étnicos o comunidades culturales a estudiar. A este respecto, un primer tipo de dificultades tiene que ver con el hecho de que en algunas investigaciones se delimita el colectivo objeto de estudio de una manera excesivamente amplia (nacionalidad, idioma, color de la piel), mientras que en otros se concibe a los grupos étnicos como entidades uniformes o estáticas, obviando las diferencias intragrupales.

Las categorizaciones amplias dificultan la interpretación de los datos y pueden suscitar inferencias erróneas, ya que esos atributos por sí mismos no tienen porque coincidir con la comunidad tal y como es percibida por sus miembros, ni con una definición de comunidad basada en aspectos contextuales, cognitivos o históricos (Maya y Martínez 2002: 124-132). Estas delimitaciones excesivamente amplias y poco significativas suelen ir unidas a la idea de que existen escasas diferencias individuales entre los miembros del colectivo en cuestión. Sin embargo, detrás de la aparente homogeneidad de algunas comunidades étnicas hay grandes diferencias que aconsejan la identificación de subgrupos. Por ejem-

\footnotetext{
${ }^{5}$ Sujetos, por tanto, a las leyes migratorias del país receptor.
} 
plo, los miembros de algunas comunidades étnicas difieren en términos de identificación con el grupo, así como en la medida en que participan de los valores del mismo. Hay una desigual distribución de los compromisos culturales y la afirmación de rasgos idiosincrásicos es una fuente adicional de heterogeneidad que impide suponer que la pertenencia a un grupo supone necesariamente compartir sus valores normativos. Por otro lado, además de las diferencias intragrupo hay que añadir el hecho de que estas comunidades étnicas están expuestas a socializaciones múltiples que producen hibridaciones: los medios de comunicación, los centros de enseñanza o las asociaciones ponen en circulación imágenes que son absorbidas por diferentes individuos.

Maya y Martínez han señalado tres formas de afrontar estas dificultades. La primera es dividir en subgrupos las categorías más amplias. Una segunda posibilidad consiste en medir la fortaleza de sus compromisos culturales. En tercer lugar, también se puede recurrir a evaluar la identidad social percibida. Estas tres fórmulas permitirían partir de una concepción realista de los grupos inmigrados y evitar una determinación demasiado estricta y rígida de los mismos (2002: 128).

\section{Las dificultades para elaborar muestras representativas}

El cuarto ámbito de problemas originados por la ausencia de superación del nacionalismo metodológico se refiere al diseño de muestras representativas, uno de los aspectos de mayor importancia en cualquier investigación social. El diseño de una muestra representativa con población inmigrante se enfrenta a problemas como la falta de información censal fiable, la propia irregularidad de su situación, el rol atribuido a la mujer, las largas jornadas laborales que los hacen ilocalizables y la desconfianza ante cualquier investigación. Además, la concentración residencial es una característica de este fenómeno que genera dificultades añadidas a los habituales procedimientos de muestreo. Si a ello se suma el hecho de que, por un lado, constituyen minorías étnicas, y por otro, se encuentran sometidas a procesos de discriminación social, no es difícil imaginar porque se convierten en un verdadero reto metodológico para los procedimientos convencionales de muestreo en la investigación social. Forman una población heterogénea de cuyas características y parámetros estadísticos no se tiene suficiente información, y por eso, la accesibilidad a los entrevistados y la representatividad de la muestra constituyen un verdadero quebradero de cabeza para cualquier investigador social que se las vea con este objeto de estudio. Por todo ello, en las encuestas con población inmigrante ha predominado el uso de muestras intencionales, los estudios de caso referidos a colectivos específicos y el manejo de referencias poblacionales parciales (Maya 2001). Ante estas dificultades, no es extraño que numerosos investigadores acaben concentrándose en aquellos subgrupos de la población que les resultan directa, o indirectamente, más accesibles. Así, las encuestas se plantean a muestras fijas independientes según la naciona- 
lidad del entrevistado. En estos casos, la representatividad será siempre muy discutible. En otras ocasiones, incluso se llega a renunciar a la representatividad muestral, lo que no deja de ser sorprendente cuando se trata de investigaciones realizadas desde instituciones científicas y universitarias.

Para conseguir una muestra representativa que recoja la diversidad y heterogeneidad del propio grupo étnico, aunque se trata de un procedimiento que atenta contra los supuestos del muestreo aleatorio, se suele establecer una serie de cuotas que incluyan aquellos segmentos que a priori se revelan como particularmente dificultosos. De ese modo, habría que entrevistar, tanto a los que desconocen el castellano como a los que lo conocen, a los que se encuentran «sin papeles» y a los que han regularizado su situación, a los que tienen unos ingresos más elevados, a los de primera generación y a los de segunda generación, a los que se concentran en los barrios de concentración étnica y a los que se hallan dispersos. Este último aspecto, el de la dispersión, ha conducido a algunos investigadores a diferenciar diversos tipos de zonas de cara a plantear la selección de sus observados o informantes. Así, por ejemplo, se podría distinguir entre núcleos históricos de grandes ciudades densamente poblados por población inmigrada, barrios periféricos con alta presencia de población de origen inmigrante, áreas donde los inmigrantes trabajan además de residir, y por último, áreas exclusivamente residenciales para los inmigrantes.

Los procedimientos que se han propuesto para sortear las mencionadas dificultades suelen tener que ver con el desarrollo de alguna estrategia para lograr acceder a la comunidad nacional de interés. A este respecto hay quien ha recomendado la difusión del proyecto de investigación, el establecimiento de contacto con representantes de la comunidad nacional en cuestión, la presentación del estudio en lugares de encuentro habitual y la realización de la entrevista en centros comunitarios (Maya y Martínez 2002: 142-143). En relación con el procedimiento para incrementar la tasa de respuesta ${ }^{6}$, lo más adecuado parece el recurso a entrevistadores del mismo grupo étnico, hecho que obviamente facilitaría el acceso y el establecimiento de la interacción.

En segundo lugar, el diseño de una muestra representativa también se enfrenta a problemas cuando lo que se pretende es conocer las opiniones y las actitudes de la población autóctona hacia los inmigrantes. Tanto es así que uno de los principales objetivos de las encuestas de este tipo (identificar la presencia de actitudes de naturaleza xenófoba o racista en zonas de máxima afluencia y concentración de población inmigrante) se convierte en tarea harto difícil como consecuencia de la habitual adopción de diseños muestrales con afijación proporcional. De manera que, dado que los inmigrantes se suelen concentrar en determinadas zonas geográficas, las encuestas que se elaboran basándose en muestras representativas de la población española no son capaces de reflejar los cambios de clima social que se registran en esos lugares concretos. Así, si los in-

${ }^{6}$ Problema éste que podría acabar afectando a la validez de constructo y, por tanto a la validez externa.

EMPIRIA. Revista de Metodología de Ciencias Sociales. N.o 13, enero-junio, 2007, pp. 101-117.

ISSN: 1139-5737 
migrantes se concentran en determinadas zonas geográficas, las encuestas que no diseñen muestras específicas para esas zonas de máxima concentración pueden tardar muchos años en certificar la emergencia del más mínimo atisbo de racismo. Como señaló hace algunos años Antonio Izquierdo, «los inmigrantes se juntan en unas pocas zonas las encuestas aludidas no son capaces de reflejar el cambio del clima social en esos lugares concretos», de manera que otros deberán ser «los ingenios a utilizar para percibir la onda del racismo» (Izquierdo 1996: 154-155).

También en estos casos es frecuente la existencia de una clara inadecuación entre la realidad de la inmigración y los diseños muestrales habituales en los estudios de opinión pública realizados por medio de encuestas estadísticas, en los que tiene la misma probabilidad de ser entrevistado un habitante de la provincia de Almería, con uno de los más elevados índices de población extranjera de todo el país, que otro de Soria, donde el índice registrado es uno de los más bajos. Como ha señalado Carmen González, «ambos individuos viven en contextos tan diferentes respecto al fenómeno de estudio y tienen informaciones tan distintas que resulta difícil considerar agregables sus respuestas» (González 2004: 14). Por tanto, la inmigración debería tratarse en este tipo de estudios de forma segmentada, por territorios, en función de la densidad inmigrante existente en cada uno de ellos, de modo que se garantice la representatividad de la submuestra de ciudadanos españoles que conviven con población inmigrante.

Las características de las poblaciones desplazadas y receptoras, junto a las condiciones de asentamiento a las que se ven expuestas las primeras, son tan diversas que resulta más difícil extraer generalizaciones simples sobre el proceso migratorio o las pautas de integración personal. Por otro lado, el fuerte carácter sociográfico y psicográfico que ha invadido la investigación sobre inmigración en España (Brunet y Alarcón 2001: 23), muestra aún otro aspecto que dificulta la posibilidad de estudiar los procesos de cambio: la imposibilidad de realizar estudios sistemáticos o de seguimiento. La mayoría de estudios se limitan a un grupo particular, en un momento concreto, en un espacio limitado y sobre una temática determinada. De ese modo se evitan (o se redimensionan, según los casos) muchos de los problemas técnicos relacionados con la representatividad de las muestras en investigaciones con inmigrantes (Rinken 2003: 159). Estos planteamientos relativos a los diseños de investigación son los que han propiciado que en España haya habido una proliferación de estudios relativos a determinados colectivos (ecuatorianos, peruanos, marroquíes...), realizados en ámbitos regionales e incluso locales (la inmigración en Murcia, la inmigración en Cataluña...), y referidos a determinados aspectos específicos (la salud, la educación, el trabajo, la vivienda). De tal manera que si, como afirma irónicamente García Borrego (2001: 152), pensáramos en un sencillo mecanismo combinatorio de estos tres criterios (colectivos, regiones, temas), se podría llegar a generar un vastísimo y fragmentado número de posibilidades de investigación cuyo agotamiento difícilmente se alcanzaría. 


\section{DISCUSIÓN Y CONCLUSIONES}

Este trabajo ha partido de la constatación de un amplio número de problemas técnico-metodológicos en la práctica de la investigación social de las migraciones internacionales, en relación tanto con aquellos estudios que exploran las actitudes de la población autóctona hacia los inmigrantes, como con aquellos cuyo universo de estudio se circunscribe a la población inmigrante. Sin perjuicio de que a lo largo del trabajo se haya hecho alusión a algunas de las soluciones técnicas que se suelen proponer para neutralizar y superar los mencionados problemas técnico-metodológicos, este artículo ha partido de la idea de que estos problemas ponen de manifiesto la necesidad de revisar algunos de los presupuestos epistemológicos y metodológicos sobre los cuales se diseñó el edificio de la ciencia sociológica en el periodo histórico de la modernidad.

Sobre este panorama, este trabajo se ha planteado el objetivo de esclarecer y analizar un presupuesto metodológico y epistemológico de cuyas inercias y seguimiento implícito por parte de la comunidad de investigadores y científicos sociales son deudores algunos de los problemas técnicos que se plantean en el estudio sociológico de las migraciones internacionales: el «nacionalismo metodológico». A partir de ahí hemos identificado los principales problemas técnico-metodológicos que genera y hemos formulado algunas reflexiones orientadas a establecer una guía para el diseño y la realización de futuras investigaciones empíricas. En todo caso, este trabajo no es más que una aproximación tentativa e inicial a un campo de investigación que requerirá ulteriores esfuerzos que permitan superar las inequívocas dificultades a las que la investigación social se enfrenta en la actualidad.

El surgimiento de la ciencia sociológica en un momento histórico de auge del estado-nación como forma de organización política ha invisibilizado el carácter histórico de la conexión entre estado, sociedad y territorio. Esta «comunión isomórfica» ha mutilado los objetos de estudio a ámbitos nacionales y ha dificultado, en la práctica, la investigación de realidades sociales de naturaleza internacional y transnacional. Aunque otros ámbitos de la vida social actual también se ven afectados por este síndrome, dado el contexto de creciente globalización en que se encuentra la humanidad en los prolegómenos del siglo XXI, el campo de estudio de las migraciones internacionales se ha visto especialmente afectado por ello, ya que ha eliminado de cuajo la posibilidad de estudiar los procesos migratorios desde la perspectiva de las comunidades de origen. Todo ello se ha consolidado aún más en un contexto en que las administraciones locales, autonómicas o estatal, han creado una elevada demanda de estudios sociológicos sobre inmigración, referidos exclusivamente a sus correspondientes ámbitos territoriales, en los que acaban produciéndose una grave confusión entre objeto social y objeto de estudio sociológico.

El actual contexto de globalización está «pasando factura» a algunos de los «préstamos epistemológicos» sobre los que se construyó la sociología como ciencia en pleno periodo de la modernidad. La ciencia sociológica, y con ella su 
apuesta técnico-metodológica nacieron y comenzaron a desarrollarse en un momento de «comunión isomórfica» entre la sociedad, el estado y el territorio. Esta «comunión isomórfica» se estableció sobre el auge y primacía del estado-nación como modelo y unidad de organización política. Este hecho condicionó profundamente el proyecto sociológico de un modo que sólo se ha hecho perceptible en el actual contexto de «ruptura de las ecuaciones de la modernidad» (PérezAgote 2005).

Nuestro trabajo ha mostrado la existencia de problemas relacionados con la elaboración de los cuestionarios y el diseño de muestras representativas cuyo nexo común radica en la aplicación de procedimientos estandarizados sobre la presunción de existencia de una «cultura nacional homogénea», una «codificación lingüística única» y una «accesibilidad equiprobable», cuando, en realidad, la población inmigrante introduce «heterogeneidad cultural», es de «desigual accesibilidad» y resulta de «difícil localización».

En definitiva, el artículo ha puesto de manifiesto la necesidad de sustituir el «nacionalismo metodológico» por un «cosmopolitismo metodológico». El primero ha impregnado y determinado la forma de trabajar en ciencias sociales. Es necesario, por tanto, crear una perspectiva de observación que resucite la original curiosidad sociológica y propicie una apertura temática, metodológica y organizativa a la posibilidad de una realidad cosmopolita. Pero ello no es tarea fácil. En primer lugar porque aunque pudiera existir un cierto consenso en el diagnóstico, aún no están claros los cimientos de lo que debería ser el nuevo paradigma. En segundo lugar porque la ciencia social es una empresa colectiva, el proyecto y la obra de una comunidad de investigación internacional, y esto implica la existencia de una serie de inercias cuya evolución y cambio a buen seguro requerirá mucho tiempo.

\section{BIBLIOGRAFÍA}

ANDERson, B. (1983): Imagined Communities: Reflections on the Origins and Spread of Nationalism. London: Verso.

BACHELARD, G. (1949): Le rationalisme appliqué. Paris: PUF.

BeCK, U. (1999): ¿Qué es la globalización? Barcelona: Paidós.

- (2004): Poder y contrapoder en la era global. Barcelona: Paidós.

- (2005): La mirada cosmopolita o la guerra es la paz. Barcelona: Paidós.

BLANCO, C. (2000): Las migraciones contemporáneas, Madrid: Alianza Editorial.

Bourdieu, P., Chamboredou, J.C., y PASSERON, J. C. (1976): El oficio de sociólogo. Madrid: Siglo XXI.

Breully, J. (1992): Nationalism and the State. Manchester University Press.

BRUNET, I. y AlARCóN, A. (2001): «Globalización y migraciones». Sistema, 165, Madrid: Fundación Sistema, pp. 23-40.

Cohen, R. y Kennedy, P. (2000): Global Sociology. London: Macmillan Press Ltd.

ESCRIVÁ, A. (2003): «Inmigrantes peruanas en España. Conquistando el espacio laboral extradoméstico». Revista Internacional de Sociología, 36, pp. 59-83. 
GARCÍA BoRREGO, I. (2001): «Acerca de la práctica y la teoría de la investigación sobre inmigración en España», Empiria, 4, Madrid: UNED, pp. 145-162.

GELlNER, E. (1983): Nations and Nationalism. Oxford: Blackwell.

GIDDENS, A (1986): The constitution of society, Cambridge: Polity Press

GONZÁLEZ ENRÍQUEZ, C. (2004): «El análisis de la opinión pública sobre la inmigración». 4 Congreso sobre la Inmigración en España. Universitat de Girona.

Gregorio, C. (1998): Migración femenina. Su impacto en las relaciones de género, Madrid: Editorial Narcea.

IBÁÑEZ, J. (1994): «Perspectivas de la investigación social: el diseño en las tres perspectivas». En García Ferrando, M., Ibáñez, J. Alvira, F. (comp.): El análisis de la realidad social. Métodos y técnicas de investigación. Madrid: Alianza.

IOÉ (1999): Inmigrantes, trabajadores, ciudadanos: una visión de las migraciones desde España, Valencia: Universitat de Valencia.

IZQUIERDO, A. (1996): La inmigración inesperada, Madrid: Editorial Trota.

LACOMBA, J. (2004): «Migración y desarrollo rural en Marruecos. El papel de los emigrantes y sus asociaciones», en Escrivá, A. y Ribas, N. (coords.), Migración y desarrollo, Córdoba: CSIC, pp. 185-212.

MAYA, I. (2001): «Sesgos de medida y problemas de muestreo en las en cuestas de poblaciones inmigrantes». Metodología de Encuestas, 3 (2), pp. 197-213.

MAYA, I. y MARTíNEZ, M. F. (2002): «El estudio de la adaptación psicológica de los inmigrantes», en Checa (ed.) Las migraciones a debate, Barcelona: Icaria.

Mohatar, M., Martín, A. y RodríGuez, E. (2004): «Abdelmalek Sayad, fundamentos epistemológicos para una ciencia de la emigración-inmigración». Cuarto Congreso sobre la Inmigración en España. Universitat de Girona.

PARdo Avellaneda, R. (1992): «Globalización, cambio disciplinar y teoría sociológica: Notas metodológicas para una Sociología del Sistema Mundial». En Moya, C., PérezAgote, A., Salcedo, J. y Tezanos, J. F. (comp.): Escritos de Teoría Sociológica en Homenaje a Luis Rodríguez Zúñiga. Madrid: CIS.

PÉREZ-AgOTE, A. (2005): «En la era global: ruptura de ecuaciones y dicotomías de la modernidad». En Ariño, A (coord.): Las encrucijadas de la diversidad cultural. Madrid: CIS.

RAMíREZ, A. (1998): Migraciones, género e Islam. Mujeres marroquíes en España. Madrid: Agencia Española de Cooperación Internacional.

RinKEN, S. (2003): «Las condiciones de vida de la población inmigrante». Metodología de Encuestas, Vol. 5, Núm. 2, pp. 151-169.

SAYAD, A. (1984): «Tendances et courants des publications en sciences sociales sur l'immigration en France depuis 1969». Current Sociology, 32, pp. 219-304.

SAYAD, A. (1996): «L'immigration et la pensée d'État. Réflexions sur la double peine», en Palidda, S. (comp.), Délit d'immigration : la construction sociale de la déviance et de la criminalité parmi les immigrés en Europe. Bruselas : Communauté européenne, pp. 11-29.

SkLAIR, L. (1995): Sociology of the Global System, John Hopkins University Press.

Smith, A. D. (1979): Nationalism in the Twentieth Century, Oxford University Press.

SMith, A.D. (1986): The Ethnic Origins of Nations. Oxford: Blackwell.

SuÁrEZ, L. (1998): «Los procesos migratorios como procesos globales. El caso del transnacionalismo senegalés». Ofrim Suplementos (diciembre), pp. 39-63.

ToRnos, A. et alii (1997): Los peruanos que vienen. Quiénes son y cómo entienden típicamente la inmigración los inmigrantes peruanos. Madrid: UPC. 
TURNER, B. S. (1990): «The two faces of Sociology. Global or National? Featherstone, M (ed) Global Culture: Nationalism, Globalization and Modernity. London: Sage Publications, pp. 343-358.

VALLeJo, A. (2004): «El viaje al Norte. Migración transnacional y desarrollo en Ecuador», en Escrivá, A. y Ribas, N. (coords.), Migración y desarrollo, Córdoba: CSIC, pp. 111-148.

Wallerstein, I. (1974): The Modern World System, New York: Academic Press. 


\title{
RESUMEN
}

La globalización ha evidenciado la necesidad de cuestionar el «nacionalismo metodológico» como presupuesto fundamental de la primera modernidad. Este cuestionamiento rompe la asunción de que los contornos de la sociedad coinciden con los del estado-nación, y supone un desafío epistemológico para la sociología, que desde su nacimiento adoptó un esquema de clasificación del espacio social que podría denominarse isomorfismo estado-sociedad. En este artículo realizamos una reflexión sobre los desafíos epistemológicos y metodológicos que las migraciones internacionales suponen para la sociología y las prácticas de investigación social mayoritarias, que generalmente arrastran inercias y presupuestos epistemológicos anclados en las características de las sociedades de la primera modernidad.

\section{PALABRAS CLAVE}

Migraciones internacionales, metodología, nacionalismo metodológico.

\begin{abstract}
Globalization has evidenced the necessity to question the «methodological nationalism» as fundamental assumption of the first modernity. This question breaks the assumption that the contours of the society coincide with those of the nation-state, and it supposes an epistemological challenge for the Sociology that adopted an outline of classification of the social space that could be denominated, from its birth, state-society isomorphism. In this paper we carry out some considerations on the epistemological and methodological challenges that the international migrations suppose for the Sociology and the main practices of social empirical research that generally drag inertias and epistemological assumptions anchored in the features of the societies of the first modernity.
\end{abstract}

\section{KEY WORDS}

International migrations, methodology, methodological nationalism. 